\title{
Modulating Autoimmunity against LDL: Development of a Vaccine against Atherosclerosis
}

\author{
${ }^{1}$ Cardiology and Angiology I, University Heart Center and Medical \\ Center - University of Freiburg, Germany \\ 2 Faculty of Medicine, University of Freiburg, Freiburg, Germany \\ 3 Facultad de Farmacia y Bioquímica, Instituto de Bioquímica y \\ Medicina Molecular (IBIMOL), Universidad de Buenos Aires, \\ CONICET, Buenos Aires, Argentina \\ ${ }^{4}$ Spemann Graduate School of Biology and Medicine (SGBM), \\ University of Freiburg, Germany
}

Timoteo Marchini ${ }^{1,2,3,4}$ Tijani Abogunloko ${ }^{1,2,4}$ Dennis Wolf ${ }^{1,2}$

Hamostaseologie 2021;41:447-457.
Address for correspondence Dennis Wolf, MD, Cardiology and Angiology I, University Heart Center Freiburg, Hugstetterstraße 55, 79106 Freiburg, Germany

(e-mail: dennis.wolf@universitaets-herzzentrum.de).

\section{Abstract}

Keywords

- atherosclerosis

- vaccination

- T cells

- antibodies

- autoimmunity

Zusammenfassung

Schlüsselwörter

- Atherosklerose

- Impfung

- T Zelle

- Antikörper

- Autoimmunität
Atherosclerosis is a chronic inflammatory disease of the arterial wall that leads to the build-up of occluding atherosclerotic plaques. Its clinical sequelae, myocardial infarction and stroke, represent the most frequent causes of death worldwide. Atherosclerosis is a multifactorial pathology that involves traditional risk factors and chronic lowgrade inflammation in the atherosclerotic plaque and systemically. This process is accompanied by a strong autoimmune response that involves autoreactive $T$ cells in lymph nodes and atherosclerotic plaques, as well as autoantibodies that recognize lowdensity lipoprotein (LDL) and its main protein component apolipoprotein B (ApoB). In the past 60 years, numerous preclinical observations have suggested that immunomodulatory vaccination with $\mathrm{LDL}, \mathrm{ApoB}$, or its peptides has the potential to specifically dampen autoimmunity, enhance tolerance to atherosclerosis-specific antigens, and protect from experimental atherosclerosis in mouse models. Here, we summarize and discuss mechanisms, challenges, and therapeutic opportunities of immunomodulatory vaccination and other strategies to enhance protective immunity in atherosclerosis.

Die Atherosklerose stellt eine chronisch entzündliche Erkrankung der Arterienwand dar, die zur Bildung von Gefäß-verengenden atherosklerotischen Plaques führt. Ihre klinischen Folgen, Herzinfarkt und Schlaganfall, repräsentieren die weltweit häufigsten Todesursachen. Der Erkrankung liegt ein multifaktorieller Krankheitsprozess zu Grunde, der traditionelle Risikofaktoren und eine chronische lokale und systemische Entzündungsreaktion umfasst. Die Entstehung der Atherosklerose wird von einer starken Autoimmunreaktion begleitet, an der autoreaktive T-Zellen in Lymphknoten und atherosklerotischen Plaques sowie Autoantikörper beteiligt sind, die gegen lowdensity lipoprotein (LDL) Cholesterin und Apolipoprotein B (ApoB) gerichtet sind. received

July 5,2021

accepted after revision

October 4, 2021
DOI https://doi.org/

10.1055/a-1661-1908.

ISSN 0720-9355. (c) 2021. The Author(s).

This is an open access article published by Thieme under the terms of the Creative Commons Attribution-NonDerivative-NonCommercial-License, permitting copying and reproduction so long as the original work is given appropriate credit. Contents may not be used for commercial purposes, or adapted, remixed, transformed or built upon. (https://creativecommons.org/ licenses/by-nc-nd/4.0/)

Georg Thieme Verlag KG, Rüdigerstraße 14, 70469 Stuttgart, Germany 
Vielfältige präklinische Untersuchungen aus den vergangenen 60 Jahren konnten zeigen, dass eine immunmodulatorische Impfung mit LDL, ApoB und ApoB-Peptiden das Potenzial hat, die Autoimmunität in er atherosklerotischen Plaque abzuschwächen, eine Toleranz gegenüber Arteriosklerose-spezifischen Antigenen auszubauen und vor Atherosklerose in Mausmodellen zu schützen. In diesem Artikel diskutieren wir die Mechanismen, Herausforderungen und therapeutischen Möglichkeiten einer immunmodulatorischen Impfung und anderer Strategien, die zur einer Stärkung der protektiven Immunantwort in der Atherosklerose führen.

\section{Introduction}

Atherosclerosis is now recognized as a chronic inflammatory disease of middle- to large-size arteries that is characterized by the development of occluding plaques in the subendothelial intimal layer. ${ }^{1}$ Its clinical complications, myocardial infarction (MI) and stroke, are the leading causes of death worldwide. ${ }^{2}$ While originally perceived as a lipid-storage disease of the arterial wall with an excessive accumulation of low-density lipoprotein cholesterol (LDL-C), ${ }^{3}$ it is now established that the progression of atherosclerotic plaques is driven by a chronic low-grade inflammatory and immune response encompassing inflammatory cells of myeloid origin and of the adaptive immune system. ${ }^{4,5}$ Epidemiologic, preclinical, and interventional studies have demonstrated that in addition to the traditional risk factors smoking, hypertension, obesity, diabetes, and environmental stressors, LDL-C is the main culprit of atherosclerosis., ${ }^{6,7}$ LDL-C continuously accumulates in the subintimal space of arteries, where it is oxidatively modified and taken up by tissue-resident macrophages, which become "foam cells" and secrete proinflammatory cytokines, such as interleukin (IL)-1 $\beta^{8}$. LDL-C-lowering strategies promote plaque regression, inhibit macrophage proliferation, and reduce cardiovascular mortality. ${ }^{7,9}$ Besides the myeloid cellular response, LDL-C initiates an autoimmune response in atherosclerotic plaques with autoreactive $\mathrm{CD}^{+} \mathrm{T}$-helper cells and Bcell-derived autoantibodies that target LDL and its core protein, apolipoprotein $B(A p o B) .5,10,11$ The modulation of this autoimmune response with immunomodulatory vaccination strategies has been increasingly investigated in the last decades. Here, we present and discuss the development of a vaccine against atherosclerosis.

\section{T-Cell Immunity in Atherosclerosis}

$\mathrm{T}$ cells and B cells represent the adaptive limb of cellular and humoral immunity against pathogens, such as bacteria or viruses. B cells target pathogens by plasma cell-derived immunoglobulin $\mathrm{G}$ ( $\mathrm{IgG}$ ) antibodies, $\mathrm{CD}^{+}$cytotoxic T cells neutralize infected cells by cytotoxic mechanisms, and $\mathrm{CD} 4^{+} \mathrm{T}$-helper cells $\left(\mathrm{T}_{\mathrm{H}}\right)$ orchestrate the adaptive immunity by secreting cytokines that can either dampen or accelerate the immune response or can exhibit cytotoxic effects themselves. ${ }^{12}$ The recognition of cognate antigens by $B$ and $T$ cells is facilitated by specific immunoreceptors on the cell surface, the B cell (BCR) and T-cell receptor (TCR). These have the ability to either bind complex antigens (BCR) or an antigen-derived peptide presented on major histocompatibility complex (MHC)-I (CD8 $\left.{ }^{+}\right)$ or MHC-II $\left(\mathrm{CD}^{+}\right){ }^{12}$ Besides B and T cells, other immune cell populations are relevant in atherosclerosis. ${ }^{5} \mathrm{~T}$ cells are the largest leukocyte population in human atherosclerotic plaques, while B cells are found only in relevant quantities in the adventitia of the vessel wall. ${ }^{13,14}$ The activation of $\mathrm{CD} 4^{+} \mathrm{T}$ cells in the plaque requires antigen presentation on MHC-II by antigen-presenting cells (APCs), such as dendritic cells or plaque macrophages. ${ }^{5,11,15}$ Antigen recognition, along with costimulatory signals from the APC, promotes the differentiation and activation of $\mathrm{T}_{\mathrm{H}}$ cells. ${ }^{16}$ As a result, naive T cells develop into effector $\mathrm{T}\left(\mathrm{T}_{\text {eff }}\right)$ cells that express distinct intracellular transcription factors and cytokines. $\mathrm{T}_{\text {eff }}$ cells have different and partially contrasting roles in atherosclerotic disease.

A proportion of lesional $\mathrm{CD}^{+}{ }^{+} \mathrm{T}$ cells in humans are proatherogenic $T_{H} 1$ cells that express the transcription factor T-bet and secrete interferon (IFN)- $\gamma \cdot{ }^{17}$ On the contrary, T regulatory $\left(\mathrm{T}_{\text {reg }}\right)$ cells are characterized by the expression of the transcription factor FoxP3 and IL-2 receptor (CD25). $\mathrm{T}_{\text {reg }}$ cells maintain self-tolerance by secreting the immunosuppressive cytokine IL-10, transforming growth factor (TGF)- $\beta$, and by direct contact inhibition of $\mathrm{T}_{\text {eff }}$ cells. ${ }^{18,19} \mathrm{~T}_{\text {reg }}$ cells in the plaque induce an alternative activation pathway in macrophages, block pathogenic $\mathrm{T}_{\mathrm{H}} 1$ immunity, resolve inflammation, and support plaque regression in the mouse. ${ }^{20}$ Circulating $\mathrm{T}_{\text {reg }}$ numbers and plasma IL-10 levels are negatively correlated with human cardiovascular disease. ${ }^{21,22} \mathrm{~T}_{\mathrm{H}} 17$ cells express the transcription factor RORYT, produce IL-17, are central for mucosal immunity, and have been associated with autoimmune disease. ${ }^{23}$ While some experimental studies in the mouse showed a proatherogenic role of $\mathrm{T}_{\mathrm{H}} 17$ cells, others demonstrated atheroprotective properties, or no effect. ${ }^{24} \mathrm{~T}$-follicular helper cells $\left(\mathrm{T}_{\mathrm{FH}}\right)$ express Bcl-6 and provide support for B cells for antibody isotype switching. ${ }^{25} \mathrm{~T}_{\mathrm{FH}}$ cell depletion protects from experimental atherosclerosis. ${ }^{26} \mathrm{~T}_{\mathrm{FH}}$ represents a direct link between humoral and cellular immunity. Antigen-specific $\mathrm{CD}^{+} \mathrm{T}$ cells in the murine atherosclerotic plaque show mixed $\mathrm{T}_{\text {reg, }}, \mathrm{T}_{\mathrm{H}} 17$, and $\mathrm{T}_{\mathrm{H}} 1$ cells. ${ }^{27}$ These seem to originate from initially immunosuppressive FoxP3 ${ }^{+} \mathrm{T}_{\text {reg }}$ cells, which downregulate FoxP3 expression and become exT $\mathrm{T}_{\text {reg }}$ cells. ${ }^{26-30}$ Many $\mathrm{CD}^{+}$ $\mathrm{T}$ cells in the atherosclerotic plaque in the mouse express low levels of FoxP3 as well as IFN- $\gamma$ and T-bet. ${ }^{27,29,30}$ These mixed $\mathrm{T}_{\mathrm{H}}$ cells seem to account for up to $50 \%$ of lesional T cells. ${ }^{27}$ 


\section{Concept of Autoimmunity in Atherosclerosis}

Autoimmunity is the abnormal response of immune cells against endogenous proteins or other structural components of the body. Protein autoantigens are recognized by $\mathrm{CD} 4^{+}$ $\mathrm{T}$ cells, which respond with proinflammatory cytokine secretion and activate other immune and stromal cell types. Autoantibodies bind to antigens, neutralize these, and build antibody-antigen complexes that may be proinflammatory. Ultimately, autoimmunity can lead to tissue damage, cell death, and organ dysfunction. ${ }^{31} \mathrm{~T}_{\text {reg }}$ cells have the ability to protect from this pathogenic response by recognizing the same self-peptides and -antigens as pathogenic T-cell clones. ${ }^{19}$ Secretion of immunosuppressive cytokines, such as IL-10, direct contact inhibition of $\mathrm{T}_{\text {eff }}$, and removal of the $\mathrm{CD}^{+} \mathrm{T}$ cell survival factor IL-2 are important $\mathrm{T}_{\text {reg }}$ effector functions. Whether atherosclerosis is a mere autoimmune disease has been a matter of discussion. Recent evidence has pointed out that autoreactivity needs to be considered as a pro-atherogenic stimulus in addition to myeloid-cell-driven inflammation and various other pathogenic mechanisms. ${ }^{5}$ Several observations suggest the presence of a strong autoimmune response in atherosclerosis: Both $\mathrm{CD}^{+}$and $\mathrm{CD} 8^{+} \mathrm{T}$ cells accumulate in the atherosclerotic plaques in mice and humans. They show signs of chronic activation, have a predominant effector-memory phenotype, and express known T-cell activation markers, including CD69, CD38, granzyme, and others, suggestive of repetitive antigen exposure by cognate, either self- or foreign antigens. ${ }^{11,14,32} \mathrm{CD} 4^{+}$T cells in human plaques show increased expression of programmed cell death protein 1 (PD-1) that is typically upregulated in chronically stimulated and exhausted $\mathrm{T}$ cells and prevents cell activation. ${ }^{14}$ These findings suggest that a natural counterregulatory checkpoint, which protects from ongoing autoimmunity, exists in atherosclerosis. ${ }^{33,34}$ Clinical checkpoint inhibition by PD-1 antibodies enhances the risk for autoimmunity in the heart. It is therefore plausible that a reversal of exhaustion may reactivate hibernating, autoreactive $T$ cells in the plaque. ${ }^{14,35}$ In the mouse plaque, $\mathrm{T}$ cells physically interact with tissue-resident APCs. ${ }^{15}$ This process is antigen dependent, involves MHC-II-dependent antigen presentation, and drives the secretion of proinflammatory cytokines by $\mathrm{T}$ cells. ${ }^{15}$ Antigen presentation and costimulation can be simulated in vitro in restimulation assays with plaque-derived T cells, APCs, and known self-peptides or more complex antigens in rodents and mice. ${ }^{10,27,36}$ A proportion of T cells secretes IFN- $\gamma^{15}$ and proliferates when restimulated with LDL or peptides derived from ApoB in an MHC-IIdependent fashion. ${ }^{10,27,36}$ ApoB-specific $T_{H}$ cells have been detected in humans by MHC-II tetramers ${ }^{37}$ and by restimulation with ApoB peptides in peripheral blood. ${ }^{27}$ T-cell proliferation, as direct consequence of antigen presentation and costimulation, is observed in murine atherosclerotic plaques in histology and scRNAseq. ${ }^{15,32,38}$ Sequencing of the TCR in mice and humans has validated that a relevant proportion of plaque $T$ cells stems from a small number of unique, antigenspecific T cells. ${ }^{27,36,39,40}$ Whether this restriction of TCR usage observed in bulk tissue analysis is caused by $\mathrm{CD} 8^{+}$or $\mathrm{CD}^{+}$ $\mathrm{T}$ cells or both is currently unclear. In addition to a cellular response involving $\mathrm{T}$ cells, circulating autoantibodies that bind ApoB or LDL have been detected in patients with atherosclerosis. ${ }^{41}$ Autoantibodies mostly target oxidation-specific epitopes of LDL. 42,43

These findings suggest that at least a part of the pathogenic lymphocyte response in atherosclerosis is caused by autoreactivity against LDL/ApoB or other autoantigens. It was long believed that this autoimmune response would be solely pathogenic. However, initial findings with RAG-1deficient mice, which lack mature B and T cells, have suggested that adaptive immune cells do either not affect atherosclerosis or only in the very initial stages of plaque development. ${ }^{44,45}$ These studies with immunosuppressive mice remain highly controversial since mice with a severe combined immunodeficiency (scid) were partially protected from atherosclerosis. ${ }^{46}$ An explanation sparked by more recent findings is that the autoreactive response in atherosclerosis is heterogeneous, subtype- and context-dependent, and can be pro- and anti-inflammatory (immune activating and immunosuppressive) at the same time, which may explain an overall neutral net effect in $\operatorname{Rag} 1^{-/-}$mice. ${ }^{5,11}$ Indeed, ApoB-reactive $\mathrm{T}$ helper cells in the early stages of atherosclerosis seem to be immunosuppressive. ${ }^{27}$ Likewise, genetic abrogation of MHC-II-dependent antigen presentation aggravates atherosclerosis. ${ }^{47}$ These findings argue for a partially protective autoimmune response in the early stages of disease-a concept denoted as "protective autoimmunity in atherosclerosis." 48 In the later stages of atherosclerosis, the protective phenotype is lost and gradually replaced by a more pathogenic phenotype. ${ }^{11,27}$ Functionally heterogeneous subtypes are also observed in the B-cell compartment, where protective B1 cells secrete IgM antibodies that mostly protect from atherosclerosis, and conventional B2 cells that secrete IgG antibodies and likely accelerate vascular inflammation. $^{42}$ It is important to highlight that the immune system is likely more diverse than initially anticipated. Recent advances in single-cell technologies demonstrate several unexpected, partially overlapping, highly dynamic phenotypes, which are particularly evident within the population of autoreactive CD4 ${ }^{+}$T helper cells. ${ }^{11,49}$ These phenotypes dissociate from classical cellular identities, for example, $\mathrm{T}_{\mathrm{H}}$ types of immunity, and may have opposing functional outcomes despite an apparent commitment to the same $T_{H}$ type. For instance, IL-17 secretion is a hallmark of $\mathrm{T}_{\mathrm{H}} 17$ cells but depending on concomitant cytokine and transcription factor expression, IFN-g/T-bet or IL-10/FoxP3, the factual (functional) identity can range from pathogenic $\mathrm{T}_{\mathrm{H}}$ 1-like to atheroprotective $\mathrm{T}_{\text {reg-like cells. It is therefore }}$ critical to identify the precise cellular targets for atheroprotective vaccination to selectively enhance the immunosuppressive limbs of ApoB autoimmunity.

\section{Other (Auto-) Antigens in the Atherosclerotic Plaque}

Beyond LDL-C and ApoB, two other groups of autoantigens have been discussed: heat shock proteins (HSPs) and $\beta 2-$ glycoprotein I ( $\beta 2 \mathrm{GPI}){ }^{50,51} \mathrm{HSPs}$ are intracellular chaperones 
that are required to protect against physical and chemical noxes. ${ }^{52}$ Autoantibodies recognizing HSPs exist in humans and positively correlate with the presence of cardiovascular disease. ${ }^{53}$ Vaccination with peptides or the entire protein complex HSP60/65 ameliorates experimental atherosclerosis in mice. ${ }^{54}$ Whether HSPs represent autoantigens per se or caused by a molecular mimicry with HSP from foreign (bacterial) HSPs is a matter of discussion. Notably, it has been observed that bacterial HSP65 induces IgG antibodies that also bind human HSP. Human HSP shares immunodominant B cell epitopes with its bacterial counterpart. ${ }^{55}$ A similar mechanism has been proposed to explain potentially beneficial effects of vaccination against Streptococcus pneumoniae that shares epitopes with oxidatively modified LDL in humans. ${ }^{43,56} \beta 2 \mathrm{GPI}$ is a regulator of the coagulation and complement system and the target of anticardiolipin antibodies in the antiphospholipid syndrome. ${ }^{57,58} \beta 2 \mathrm{GPI}$ is located in the plasma, but has also been detected in human atherosclerotic lesions. ${ }^{59}$ Whether vaccination using $\beta 2$ GPI protects from atherosclerosis in mice is controversial. . $^{5,60,61}$

The clinical correlation of infectious disease and atherosclerosis has also sparked the idea that a proportion of $\mathrm{T}$ cells in the plaque may recognize foreign antigens, that is, peptides from bacteria or viruses. Indeed, clinical observations have suggested that varicella zoster virus (VZV) and influenza virus infection increases the risk for MI and stroke. ${ }^{62}$ Influenza vaccination ameliorates the outcome of patients with clinically relevant atherosclerosis and is therefore recommended for patients with heart disease. ${ }^{63,64}$ Several other viruses, including human cytomegalovirus, herpes simplex virus, Epstein-Barr virus, VZV, and influenza virus, have either been detected in arterial tissue or are suspected to promote inflammation of the vasculature. ${ }^{62}$ These associations, however, could be explained by indirect effects, for instance, the induction of local tissue injury, thrombotic pathways, or a systemic inflammatory response ${ }^{65,66}$ as observed in SARS-CoV-2 infection, which promotes inflammation and dysfunction of the vasculature and enhances thrombogenicity. ${ }^{67,68}$ SARS-CoV-2 viral particles have been detected in endothelial cells ${ }^{69}$ and the myocardium. ${ }^{70}$ Whether SARS-CoV-2-specific T cells are enriched in atherosclerotic plaques is currently not known.

\section{Immunomodulatory Vaccination with LDL-C|ApoB}

Up to now, vaccination with LDL and peptides from ApoB has been exclusively tested in rodents. In 1959, Gero et al were the first to observe a decrease of atherosclerotic lesion formation following a vaccination of rabbits with LDL. ${ }^{71}$ In the last decades, numerous studies in rodents have validated that vaccination with native $L D L$, oxidized $L D L$, or peptides from ApoB induces an atheroprotective T-cell response. ${ }^{50,72-80}$ The main protein immunogen in LDL is ApoB. So far, nine distinct ApoB peptides have been validated in peptide vaccination studies: p3, p6, p18, p101, p102, p103, p210, p265, and p295. ${ }^{27,37,81-84}$ In these studies, peptide vaccination was mostly tested in a preventive setting to inhibit de novo atherosclerosis in ApoE- or LDLR-deficient mice. Peptides were largely delivered subcutaneous as emulsion of peptides with complete Freund's adjuvant (CFA) as prime and subsequent boost injections intraperitoneally with incomplete Freund's adjuvant (IFA)..$^{50}$ In some reports, peptides were linked to keyhole limpet hemocyanin $(\mathrm{KLH})^{84}$ or the B subunit of cholera toxin subunit B (CTB). ${ }^{83}$ Different routes, such as intranasal delivery, have been described as well. ${ }^{83}$ Vaccination with ApoB peptides has been demonstrated to induce antigenspecific T cells, T-cell proliferation, and cytokine secretion. ${ }^{81}$ ApoB-specific $\mathrm{CD}^{+}{ }^{+} \mathrm{T}$ cells have been found in the spleen and in the peritoneal cavity, which is likely related to tested routes of vaccination. Induction of IL-10 secreting $\mathrm{T}_{\text {reg }}$ cells in the atherosclerotic aorta and spleen has been proposed as the main protective mechanism. ${ }^{82,83,85,86} \mathrm{~T}_{\text {reg-independent IL-10 }}$ secretion has also been observed ${ }^{81,87}$ as well as an inhibition of $\mathrm{T}_{\mathrm{H}} 1$ immunity. ${ }^{86}$ In conclusion of the reported mechanisms (extensively reviewed in the article by Nettersheim et $\mathrm{al}^{50}$ ), it is believed that preexisting ApoB-specific $\mathrm{T}_{\text {reg }}$ cells or IL-10 secreting non- $T_{\text {reg }}$ cells $\left(T_{R} 1\right.$ cells) selectively expand after vaccination with $A p o B$, either at the site of injection or in draining lymph nodes. Cytokines secreted by ApoB-specific $\mathrm{T}$ cells may circulate and act on atherosclerotic plaques in a remote fashion ( - Fig. 1 ). The direct migration of $\mathrm{T}$ cells into atherosclerotic lesions has been extensively studied ${ }^{89}$ but has not yet been demonstrated for vaccination-induced $T$ cells. The function of ApoB-specific T cells seems to be highly flexible. For instance, vaccination with $\mathrm{p} 6$ was atheroprotective in $\mathrm{Apoe}^{-\mathrm{I}^{-}}$ mice after a prime in CFA and four subsequent boosts in IFA. In this study, mice received an atherogenic diet for 13 weeks 1 week after the prime vaccination. ${ }^{81}$ In $A p o e^{-l-}$ mice pre-fed with an atherogenic diet for 5 weeks, one prime and one boost in CFA dramatically exacerbated atherosclerotic lesion size within the next 5 weeks. ${ }^{90}$ A potential explanation for this discrepancy is that vaccination may only be capable of expanding the existing pool of antigen-specific $T$ cells with a certain phenotype but not of reversing phenotypes. As mentioned earlier, ApoB-specific $\mathrm{T}$ cells undergo a phenotypic transformation from a $T_{\text {reg }}$-like $T_{H} 17$ cell with a protective phenotype in healthy animals into a pathogenic $\mathrm{T}_{\mathrm{H}} 1$-like phenotype with proinflammatory cytokine secretion in established disease. ${ }^{27}$ Therefore, atheroprotective peptide vaccination may only be effective in the absence or in early stages of atherosclerotic disease when ApoB-specific $\mathrm{T}_{\text {reg }}$ cells dominate but not in later stages after the phenotypic switch when $\mathrm{T}_{\mathrm{H}} 1$-like pathogenic cells outnumber protective $T_{\text {reg }}$ cells. It remains, however, to be tested whether vaccination in established disease preferentially expands pathogenic T-cell clones.

\section{Vaccination to Neutralize Atherosclerosis- Relevant Proteins, Apolipoproteins, and Cells}

As mentioned earlier, vaccination is historically designed to remove target proteins, such as toxins, or other harmful noxes during infection. Therefore, vaccination against infectious agents needs to be capable of inducing highaffinity B-cell-derived IgGs that bind to immunodominant 


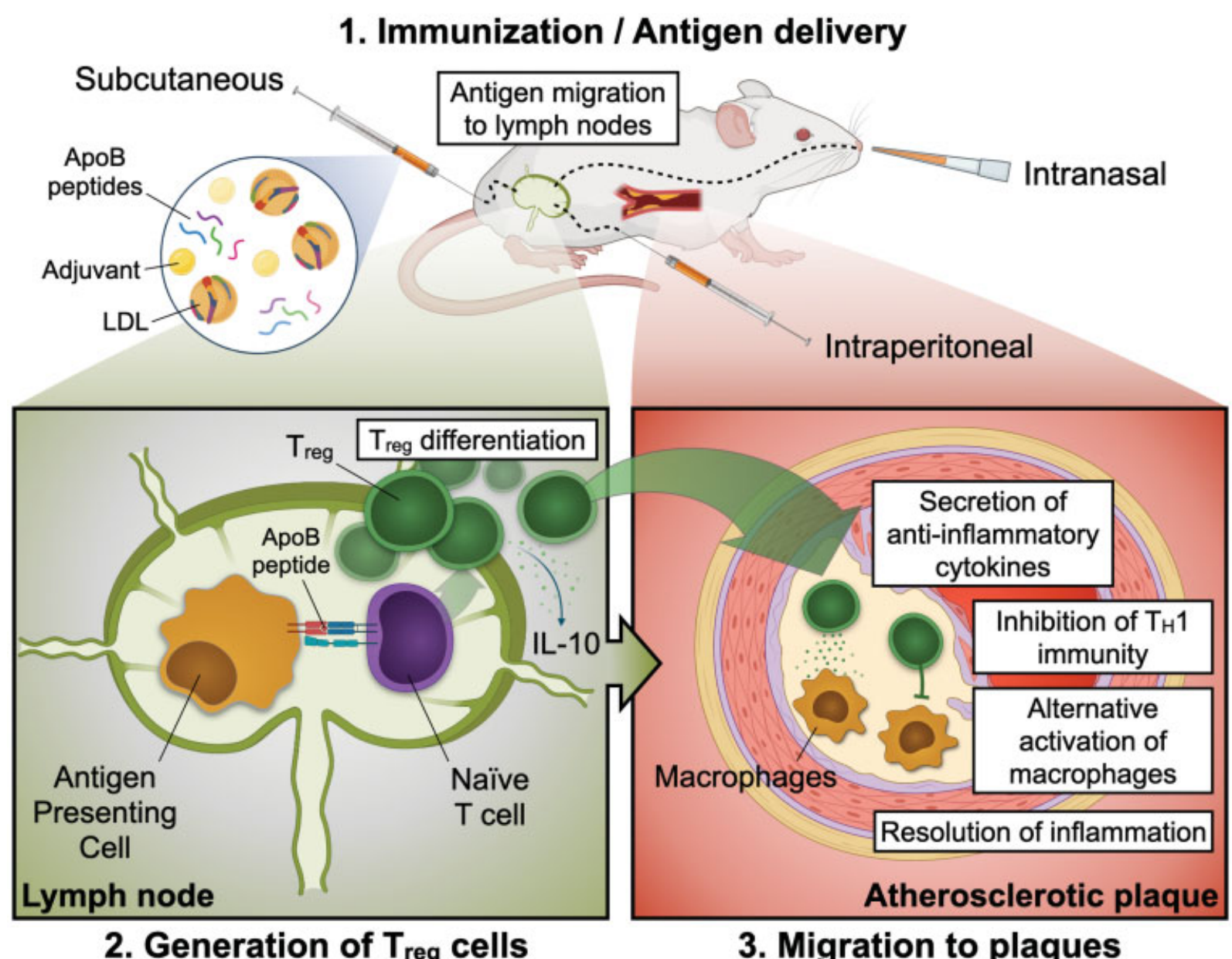

Fig. 1 Proposed mechanism of immunomodulatory LDL/ApoB vaccination in mice. A combination of autoantigens (native LDL, oxidized LDL, ApoB peptides) and the adjuvant (mostly CFA or IFA) is injected subcutaneous or in the peritoneal cavity. Intranasal application of an ApoB-cholera toxin fusion protein has also been described (1). Antigens are transported to locally draining lymph nodes, taken up by antigen-presenting cells (APCs), processed, and peptides from the antigen are presented to naive T cells. T cells are activated, and proliferate and differentiate into IL-10 secreting regulatory T cells ( $T_{\text {reg }}$ ) or IL-10 secreting non- $T_{\text {reg }}\left(T_{R} 1\right)(2)$. LDL/ApoB-specific T cells redistribute to other lymph nodes or directly migrate into atherosclerotic plaques (3). Vaccination-induced T cells secrete the immunosuppressive cytokine IL-10, which suppresses cellular proliferation and activation of effector $T$ cells. In addition, $\mathrm{T}_{\text {reg }}$ cells inhibit pathogenic $\mathrm{T}_{H} 1$ pathways in the plaque, induce alternative-activation pathways in macrophages, and support resolution of inflammation. These local and systemic effects retard atherosclerotic lesion progression. Created with Biorender.com.

epitopes and neutralize the antigen through various mechanisms. In addition, vaccination-induced IgGs serve as biomarkers of vaccination efficacy and indicate the need for booster immunization. Antigen-specific T cells may support rapid recall responses even in the absence of long-lasting $\operatorname{IgG}$ titers, as recently demonstrated for SARS-CoV-2 vaccines. ${ }^{91}$ It is important to note that the generation of neutralizing $\operatorname{IgG}$ antibodies requires a proinflammatory response with $\mathrm{T}_{\mathrm{H}} 1$ polarized $\mathrm{CD} 4^{+}$ $\mathrm{T}$ cells. This principle fundamentally differs from an immunomodulatory immunization, which aims to induce a protective response with immunosuppressive $\mathrm{T}_{\text {reg }}$ cells. Whether and how antibodies support this response is currently unknown. Yet, the induction of neutralizing IgG antibodies may be helpful to inhibit some important propagators of atherogenesis. For instance, a recent study has highlighted that naturally occurring antibodies to ALDH4A1, a mitochondrial dehydrogenase, can delay atherosclerosis progression. ${ }^{92}$ Vaccination strategies may therefore also be designed to remove endogenous proteins with a pathogenic potential through an endogenous clearance by $\operatorname{Ig} G$ antibodies as a substitution for repetitive exogenous IgG injections.

\section{Neutralizing Interleukin-12}

Neutralizing interleukin-12 (IL-12) is a $\mathrm{T}_{\mathrm{H}} 1$-inducing cytokine, which is secreted by macrophages and other APCs. Blocking IL-12 protects from atherosclerosis, likely by preventing proinflammatory and pathogenic $\mathrm{CD} 4^{+} \mathrm{T}$ cell clones and pathogenic $\mathrm{T}_{\mathrm{H}} 1$ polarization. ${ }^{93} \mathrm{LDLR}^{-1-}$ mice immunized with a complex of IL-12 and adjuvant developed anti-IL-12 antibodies that neutralized IL-12 downstream signaling and IFN- $\gamma$ secretion in T cells, resulting in smaller atherosclerotic lesions with a plaque phenotype resembling plaque stability in humans. ${ }^{94}$ Essentially, these results confirm findings from initial studies that made use of exogenous antibody injections. The main limitation of blocking IL-12 is the broad and unspecific inhibition of $\mathrm{T}_{\mathrm{H}} 1$ responses that are vital for host defense and may therefore induce relevant immunosuppression in a clinical setting. 
Vaccination as an Alternative Strategy to Lower LDL-C LDL-C is considered the main culprit of atherosclerosis. ${ }^{5}$ LDL-C lowering correlates with an improvement of cardiovascular outcomes in an almost linear fashion and current clinical guidelines recommend individual LDL-C target ranges based on the individual risk for cardiovascular disease and the presence of clinically relevant atherosclerotic cardiovascular disease (ASCVD). ${ }^{95}$ Currently, LDL-C lowering is mainly achieved by an inhibition of HMG-CoA reductase by statins, and an inhibition of cholesterol uptake in the intestine. ${ }^{95} \mathrm{An}$ alternative strategy to lower LDL-C is the inhibition of proprotein convertase subtilisin/kexin type 9 (PCSK9), which degrades the receptor for LDL and results in a diminished peripheral uptake of LDL-C. PCSK9 expression correlates with cardiovascular events and individuals with a loss-of-function mutation are greatly protected in genome-wide associations studies. ${ }^{96}$ Clinically, humanized, monoclonal antibodies against PCSK9 are now recommended in cardiovascular patients with LDL-C levels above the individual target range. ${ }^{95}$ Neutralizing antibodies against PCSK9 can also be induced in mice and primates by an immunization with virus-like particles that display PCSK9-derived peptides, ${ }^{97}$ albeit these antibodies did not seem to reduce LDL-C in preclinical studies. Another strategy is the inhibition of cholesteryl ester transfer protein (CETP), which transfers cholesterol from high-density lipoproteins (HDLs) to LDL and very-low density lipoproteins (VLDL). LDL and VLDL propagate atherosclerosis. Immunization with a fusion protein of CETP and tetanus toxin resulted in neutralizing CETP antibodies in mice. ${ }^{98,99}$

\section{Targeting Atherosclerosis-Relevant T Cells by Blocking Specific TCRs}

While immunomodulatory approaches are designed to specifically induce immunosuppressive $\mathrm{T}$-cell clones (e.g., $\mathrm{T}_{\mathrm{reg}}$ cells), it is also reasonable to discuss the therapeutic removal of pathogenic T-cell clones. This strategy requires to be most specific for ApoB-specific T cells. This technical challenge could be theoretically achieved by MHC-II tetramer-based strategies. ${ }^{100}$ Hermansson et al have proposed a less specific but effective strategy to remove $\mathrm{T}$ cells expressing the predominant TCR variable $(\mathrm{V}) \beta$ segments by neutralizing monoclonal antibodies. It is important to emphasize that $\mathrm{T}$ cells selected on broad criteria, such as TCR $\beta$ segment usage, contain other specificities beyond LDL/ApoB. In their study, LDL-specific T-cell clones mostly expressed the TCRBV31 segment. The $\mathrm{V}$ segment is required for TCR-MHC-II interaction. Vaccination of atherosclerosis-prone mice with a TCRBV31 peptide induced blocking antibodies against TCRBV31 and protected from atherosclerosis. ${ }^{36}$ It may be possible that this strategy either blocks TCR-MHC-II interactions or eliminates pathogenic T-cell clones. ${ }^{36}$

\section{Translational Strategies}

Vaccination to protect against bacterial and viral infection is the most successful intervention of medical history. ${ }^{101}$ The concept of immunomodulatory vaccination to induce a preferable immune phenotype during autoimmune disease has been mainly demonstrated in mouse models of diabetes and multiple sclerosis. ${ }^{102}$ Atheroprotective vaccination has remained at a preclinical level and only a few, recent studies have interrogated the existence of ApoB-specific $T$ cells in humans. ${ }^{27,37}$ Several questions, which are fundamental to understand human immunity against $\mathrm{ApoB} / \mathrm{LDL}-\mathrm{C}$, need to be addressed in the future to develop a vaccine against human atherosclerosis.

\section{Human Self-Peptides from ApoB}

As highlighted earlier, the induction of an immune response -either during presentation of the natural occurring antigenic peptides or of the peptide vaccine-requires a high affinity of the peptide and MHC-II. In contrast to inbred laboratory mice, which only express one variant of MHC-II (I- $\mathrm{A}^{\mathrm{b}}$ in the C57BL/6 mouse), humans express a high number of MHC-II variants with eight different class II allotypes, which results in a total of approximately 10,000 different HLA allelic forms that all bear different affinities to potential peptides. The identification of suitable peptides is therefore limited by several aspects: first, the MHC-II alleles must be determined by sequencing in every individual before vaccination. Second, every MHC-II variant would potentially require its own tested antigenic peptide in the vaccine, even if recent screening strategies have identified several peptide sequences with moderate to high affinities across several MHC-II variants. ${ }^{27}$ In addition, every peptide is likely to bind to several MHC-II alleles with different affinities. It is important to note that is has not been entirely resolved whether low- versus high-affinity peptides may promote divergent T-cell phenotypes with pro- and antiinflammatory T-cell clones simultaneously. ${ }^{103}$

\section{Adjuvants and Routes of Administration}

Immunologic adjuvants are substances that are added to the antigens to enhance the effectiveness of the immune reaction during vaccination. ${ }^{104}$ Traditional adjuvants make use of evolutionary conserved motifs, pathogen-associated molecular patterns, for example, in lipopolysaccharides that augment the immune response by binding to pattern-recognition receptors. ${ }^{105}$ Frequently used adjuvants in rodents are CFA that contains heat-inactivated Mycobacterium tuberculosis in an emulsion with mineral oil and IFA that does not contain M. tuberculosis for booster injections. ${ }^{106}$ The sequence of CFA-IFA as prime and boost injection is atheroprotective, ${ }^{107}$ while a single vaccination with CFA and the same antigen seems to be pro-atherogenic. ${ }^{90} \mathrm{CFA}$, however, induces several side effects and is therefore obsolete in clinical practice. ${ }^{108} \mathrm{In}$ contrast, many clinically used adjuvants make use of aluminum salts (alum) or CTB. One important consideration is that adjuvants alone may have the ability to modulate atherosclerosis, as shown for IFA and alum. Both seem to induce an atheroprotective immune response even in the absence of a specific antigen. ${ }^{87,109,110}$ Of the clinically used adjuvants, only Addavax, a squalene oil-based nano-emulsion, has an efficacy similar to that of CFA/IFA in a head-to-head comparison in the mouse testing ApoB vaccination in de novo atherosclerosis. ${ }^{86}$ Currently, Addavax is frequently used in flu vaccines. 
In rodents, booster injections are often made in the peritoneal cavity-a strategy that is not practical in humans. Alternative routes of antigen delivery in rodents with partially divergent pro- or anti-atherogenic effects include nasal and oral application $^{111,112}$ as well as intra- or subcutaneous injection. ${ }^{113,114}$

\section{Identification of Patients for LDL/ApoB Vaccination}

Vaccination of atherosclerosis-prone $\mathrm{Ldlr}^{-/-}$and $A p o e^{-/-}$ mice with LDL/ApoB preparations has exclusively been tested in preventative settings, where vaccination was highly efficient in preventing de novo atherosclerosis. Whether atheroprotective vaccination has the potential to dampen or even reverse established atherosclerosis remains to be tested. Particularly in light of the constantly transforming phenotype of ApoB-specific $T$ cells in the course of disease, a vaccine should be capable of reversing the phenotype of late-stage $\mathrm{T}_{\mathrm{H}} 1$-primed and pathogenic T cells ${ }^{27}$ back to an immunosuppressive $T_{\text {reg-like phenotype }}$ or to generate new $\mathrm{T}_{\text {reg }}$ cells. In addition, patients susceptible to vaccination need to be identified in clinical practice. It has been increasingly appreciated that different risk scenarios of atherosclerosis exist. Even under optimal lipidlowering therapies, a residual inflammatory risk persists. ${ }^{115}$ While this risk may be lowered by the addition of antiinflammatory therapies, a considerable high rate of event remains, giving rise to the speculation that a fraction of this excessive risk, which is currently not addressable by medical therapy, relates to immune activation. Besides immunoglobulins that recognize LDL/ApoB, the quantification of ApoB-specific $T$ cells, such as by recently introduced restimulation $^{27}$ or by tetramers, ${ }^{37}$ may help identify the suitable patient for vaccination.

\section{DNA and mRNA Vaccination}

Antigens are traditionally delivered as recombinant proteins, peptides, attenuated pathogens, and more complex formulations. DNA vaccines refer to the delivery of naked DNA or DNA packed into plasmids that encodes for the antigen. DNA vaccines have been tested in animal models of autoimmunity, including experimental autoimmune encephalomyelitis (EAE) and rheumatoid arthritis. ${ }^{116-118}$ In atherosclerosis, DNA vaccination against vascular endothelial growth factor 2 (VEGF-2) induced CD8 ${ }^{+}$cytotoxic T cells, which neutralized VEGF-2 expressing endothelial cells and protected from atherosclerosis. ${ }^{119}$ VEGF-2 is known to be expressed by stressed endothelium. mRNA vaccines contain the messenger RNA (mRNA) that codes for antigen. mRNA vaccines have recently been successfully developed against SARS-CoV-2 and promise low-cost manufacturing, validated safety profiles, rapid developments, and high potency. ${ }^{120}$ mRNA vaccines against LDL/ApoB have not yet been developed. One challenge in DNA and mRNA vaccines remains their ability to be expressed in target dendritic cells and to prevent simultaneous activation of dendritic cells (DCs). Recently, it was shown that this limitation may be circumvented with a nanoparticle-formulated 1 methylpseudouridine-modified messenger RNA that induced a strong $\mathrm{T}_{\text {reg }}$ response and prevented EAE in mice. $^{121}$

\section{Immunotherapy with Immunoglobulins}

IgG antibodies against $\mathrm{LDL}$ and $\mathrm{ApoB}$ are detectable in untreated mice and humans, correlate with atherosclerotic disease, and rise after vaccination with LDL/ApoB. ${ }^{37,42,51,72-74,76,107,122,123}$ Whether they exhibit a biological activity is uncertain. The generation of antibodies against peptides of ApoB in the inner core of LDL particles, however, renders it unlikely that these may physically interact with intact LDL particles. Instead, they may serve as biomarkers of vaccination efficacy. In addition, preclinical evidence has suggested both pro- and anti-atherogenic outcomes after passive vaccination with some IgG antibodies. ${ }^{13,124-126}$ On the contrary, most IgM antibodies are naturally occurring and target oxidation-specific epitopes with a convincing antiatherogenic function. ${ }^{42}$ Immunotherapy with injectable immunoglobulins has been tested only in humans with an IgG1 antibody targeting the oxidation-specific epitope $\mathrm{p} 45$ of ApoB (anti-oxLDL, MLDL1278A). This antibody was effective in mouse atherosclerosis ${ }^{125,126}$ and in primates. ${ }^{127}$ In the multicenter, randomized phase-II GLACIER trial (Goal of Oxidized LDL and Activated Macrophage Inhibition by Exposure to a Recombinant Antibody), MLDL1278A was tested for its efficacy to reduce arterial wall inflammation quantified by positron emission tomography (PET) imaging with ${ }^{18} \mathrm{~F}$-fluorodeoxyglucose (FDG). MLDL1278A failed to reach its primary endpoint, but many methodological weaknesses render the interpretation of GLACIER results difficult. ${ }^{128}$ In conclusion, it is still under debate whether IgG immunotherapy works in humans.

\section{TCR/CAR T-Cell Immunotherapy}

T cells expressing a chimeric antigen receptor (CAR T cells) or a transgenic $\mathrm{T}$ cell receptor have recently emerged in cancer immunology. CAR T cells are constructed to express an engineered antigen receptor, often a single-chain variable fragment (scFv) from antibodies that specifically recognizes a specific antigen on cancer cells. $\mathrm{CD}^{+}$cytotoxic T cells engineered to express a CAR can therefore be guided to neutralize cancer cells after an adoptive transfer. Similarly, TCR T cell immunotherapy bases on T cells expressing a transgenic TCR with a certain specificity. ${ }^{129}$ CAR $T$ cell therapy has been approved for leukemia and lymphoma in humans. ${ }^{130}$ Recently, it was shown that cardiac fibrosis can be prevented by redirecting $\mathrm{CD}^{+} \mathrm{T}$ cells to attack cardiac fibroblasts in mice. ${ }^{131}$ Because ApoB-reactive $\mathrm{T}_{\text {reg }}$ cells prevent murine atherosclerosis after an adoptive transfer, ${ }^{27}$ it is plausible to speculate that the infusion of engineered $\mathrm{T}_{\text {reg }}$ cells with an ApoB-reactive TCR (TCR immunotherapy) or a CAR recognizing plaque-specific proteins (CAR T-cell immunotherapy) would be effective in treating atherosclerosis in future. However, the identification of atherosclerosis-specific ligands for CAR and HLA-adapted ApoB-specific TCRs in humans remains a future challenge.

\section{Conclusion}

The recent introduction of novel LDL-lowering strategies (PCSK9), new anti-inflammatory treatments (IL-1 $\beta$ blockade by monoclonal antibodies), and novel therapies to address the 
excessive risk in patients with diabetes mellitus (SGLT-2 inhibition, GLP-1 agonism) has greatly improved medical strategies in atherosclerosis and established a novel path for precision medicine in cardiology. In addition to excessive inflammatory or metabolic risk, solid evidence from numerous preclinical and clinical studies has identified a substantial role for an immune-related pathogenesis of atherosclerosis with a humoral and cellular response against autoantigens. LDL and ApoB have been in the center of investigations in the last decades, but the exact immunodominant epitopes and potential other antigens are still unknown. "Vaccination against atherosclerosis" has emerged as a novel type of immunomodulation that holds the promise of causality, minimal sideeffects, and cost-effectiveness. Several major concepts have emerged as vaccination-based therapies: (1) passive immunization with exogenous IgG antibodies that make use of naturally occurring immunoglobulins. Albeit this type of immunotherapy has advanced into the clinical stage, early clinical results were negative; (2) vaccines that are designed to neutralize a pro-atherogenic protein by endogenously produced IgG antibodies, such as PCSK9, CETP, or ALDH4A1. These therapies, however, offer no substantial advantage over existing or future biologicals that are administered by injection; (3) tolerogenic vaccination to weaken the existing pathogenic immune response against the naturally occurring autoantigens LDL and ApoB. While this path is the most existing one and offers a truly preventative vaccination strategy, the conceptual framework, antigens, doses, routes, and vaccination pipelines will have to be clarified in future. Even if this type of vaccination will not succeed, current advances in understanding the adaptive immune response in atherosclerosis have already opened several new avenues. These strategies focus on promoting the pool of $\mathrm{T}_{\text {reg }}$ cells with injectable IL-2 ${ }^{132}$ or on an exogenous propagation of antigen-specific $\mathrm{T}_{\text {reg }}$ cells for TCR- or CAR-T-cell immunotherapy.

\section{Funding}

This project has received funding from the European Research Council (ERC) under the European Union's Horizon 2020 research and innovation program (grant agreement no. 853425). T.M. and D.W. are members of the SFB1425, funded by the Deutsche Forschungsgemeinschaft (DFG, German Research Foundation).

\section{Conflict of Interest}

The authors declare no potential conflict of interest.

D.W., T.M., and T.A. report support for the present manuscript (e.g., funding, provision of study materials, medical writing, and article processing charges) from the European Research Council (ERC) for European Union's Horizon 2020 research and innovation program (grant agreement no. 853425) and from Deutsche Forschungsgemeinschaft for SFB1425 (D.W. and T.M. are members).

\section{References}

1 Libby P. Inflammation in atherosclerosis. Nature 2002;420 (6917):868-874
2 Kruk ME, Gage AD, Joseph NT, Danaei G, García-Saisó S, Salomon JA. Mortality due to low-quality health systems in the universal health coverage era: a systematic analysis of amenable deaths in 137 countries. Lancet 2018;392(10160):2203-2212

3 Ross R. The pathogenesis of atherosclerosis-an update. N Engl J Med 1986;314(08):488-500

4 Wolf D, Zirlik A, Ley K. Beyond vascular inflammation-recent advances in understanding atherosclerosis. Cell Mol Life Sci 2015;72(20):3853-3869

5 Wolf D, Ley K. Immunity and inflammation in atherosclerosis. Circ Res 2019;124(02):315-327

6 Marchini T, Zirlik A, Wolf D. Pathogenic role of air pollution particulate matter in cardiometabolic disease: evidence from mice and humans. Antioxid Redox Signal 2020;33(04):263-279

7 Colantonio LD, Bittner V, Reynolds K, et al. Association of serum lipids and coronary heart disease in contemporary observational studies. Circulation 2016;133(03):256-264

8 Nahrendorf M. Myeloid cell contributions to cardiovascular health and disease. Nat Med 2018;24:711-720

9 Härdtner C, Kornemann J, Krebs K, et al. Inhibition of macrophage proliferation dominates plaque regression in response to cholesterol lowering. Basic Res Cardiol 2020;115(06):78

10 Stemme S, Faber B, Holm J, Wiklund O, Witztum JL, Hansson GK. $\mathrm{T}$ lymphocytes from human atherosclerotic plaques recognize oxidized low density lipoprotein. Proc Natl Acad Sci U S A 1995; 92(09):3893-3897

11 Marchini T, Hansen S, Wolf D. ApoB-specific CD4 ${ }^{+} \mathrm{T}$ cells in mouse and human atherosclerosis. Cells 2021;10(02):446

12 Zinkernagel RM, Hengartner $H$. Regulation of the immune response by antigen. Science 2001;293:251-253. Doi: 10.1126/ science.1063005. PMID: 11452115

13 Winkels $\mathrm{H}$, Wolf D. Heterogeneity of $\mathrm{T}$ cells in atherosclerosis defined by single-cell RNA-sequencing and cytometry by time of flight. Arterioscler Thromb Vasc Biol 2021;41(02):549-563

14 Fernandez DM, Rahman AH, Fernandez NF, et al. Single-cell immune landscape of human atherosclerotic plaques. Nat Med 2019;25(10):1576-1588

15 Koltsova EK, Garcia Z, Chodaczek G, et al. Dynamic T cell-APC interactions sustain chronic inflammation in atherosclerosis. J Clin Invest 2012;122(09):3114-3126

16 Neefjes J, Jongsma ML, Paul P, Bakke O. Towards a systems understanding of MHC class I and MHC class II antigen presentation. Nat Rev Immunol 2011;11(12):823-836

17 Frostegard J, Ulfgren AK, Nyberg P, et al. Cytokine expression in advanced human atherosclerotic plaques: dominance of proinflammatory (Th1) and macrophage-stimulating cytokines. Atherosclerosis 1999;145(01):33-43

18 Foks AC, Lichtman AH, Kuiper J. Treating atherosclerosis with regulatory T cells. Arterioscler Thromb Vasc Biol 2015;35(02): 280-287

19 Sakaguchi S. Naturally arising CD4+ regulatory t cells for immunologic self-tolerance and negative control of immune responses. Annu Rev Immunol 2004;22:531-562

20 Sharma M, Schlegel MP, Afonso MS, et al. Regulatory T cells license macrophage pro-resolving functions during atherosclerosis regression. Circ Res 2020;127(03):335-353

21 Mor A, Luboshits G, Planer D, Keren G, George J. Altered status of $\mathrm{CD} 4(+) \mathrm{CD} 25(+)$ regulatory $\mathrm{T}$ cells in patients with acute coronary syndromes. Eur Heart J 2006;27(21):2530-2537

22 Wigren M, Björkbacka H, Andersson L, et al. Low levels of circulating CD4+FoxP3 + T cells are associated with an increased risk for development of myocardial infarction but not for stroke. Arterioscler Thromb Vasc Biol 2012;32(08):2000-2004

23 McGeachy MJ, Cua DJ, Gaffen SL. The IL-17 family of cytokines in health and disease. Immunity 2019;50(04):892-906

24 Taleb S, Tedgui A, Mallat Z. IL-17 and Th17 cells in atherosclerosis: subtle and contextual roles. Arterioscler Thromb Vasc Biol 2015;35(02):258-264 
25 Crotty S. T follicular helper cell biology: a decade of discovery and diseases. Immunity 2019;50(05):1132-1148

26 Gaddis DE, Padgett LE, Wu R, et al. Apolipoprotein AI prevents regulatory to follicular helper $\mathrm{T}$ cell switching during atherosclerosis. Nat Commun 2018;9(01):1095

27 Wolf D, Gerhardt T, Winkels H, et al. Pathogenic autoimmunity in atherosclerosis evolves from initially protective apolipoprotein $\mathrm{B}_{100}$-reactive $\mathrm{CD} 4^{+} \mathrm{T}$-regulatory cells. Circulation 2020;142(13): 1279-1293

28 Kimura T, Kobiyama K, Winkels $\mathrm{H}$, et al. Regulatory $\mathrm{CD} 4^{+} \mathrm{T}$ cells recognize major histocompatibility complex class II moleculerestricted peptide epitopes of apolipoprotein B. Circulation 2018;138(11):1130-1143

29 LiJ, McArdle S, Gholami A, et al. CCR5+T-bet+FoxP3+ effector CD4 T cells drive atherosclerosis. Circ Res 2016;118(10):1540-1552

30 Butcher MJ, Filipowicz AR, Waseem TC, et al. Atherosclerosisdriven Treg plasticity results in formation of a dysfunctional subset of plastic IFN $\gamma+$ Th1/Tregs. Circ Res 2016;119(11): 1190-1203

31 Rosenblum MD, Remedios KA, Abbas AK. Mechanisms of human autoimmunity. J Clin Invest 2015;125(06):2228-2233

32 Winkels H, Ehinger E, Vassallo M, et al. Atlas of the immune cell repertoire in mouse atherosclerosis defined by single-cell RNAsequencing and mass cytometry. Circ Res 2018;122(12): $1675-1688$

33 Blank CU, Haining WN, Held W, et al. Defining 'T cell exhaustion'. Nat Rev Immunol 2019;19(11):665-674

$34 \mathrm{Bu}$ DX, Tarrio M, Maganto-Garcia E, et al. Impairment of the programmed cell death-1 pathway increases atherosclerotic lesion development and inflammation. Arterioscler Thromb Vasc Biol 2011;31(05):1100-1107

35 Kusters PJH, Lutgens E, Seijkens TTP. Exploring immune checkpoints as potential therapeutic targets in atherosclerosis. Cardiovasc Res 2018;114(03):368-377

36 Hermansson A, Ketelhuth DF, Strodthoff D, et al. Inhibition of T cell response to native low-density lipoprotein reduces atherosclerosis. J Exp Med 2010;207(05):1081-1093

37 Kimura T, Kobiyama K, Winkels H, et al. Regulatory CD4(+) T Cells Recognize MHC-II-Restricted Peptide Epitopes of Apolipoprotein B. Circulation 2018

38 Lutgens E, de Muinck ED, Kitslaar PJ, Tordoir JH, Wellens HJ, Daemen MJ. Biphasic pattern of cell turnover characterizes the progression from fatty streaks to ruptured human atherosclerotic plaques. Cardiovasc Res 1999;41(02):473-479

39 Paulsson G, Zhou X, Törnquist E, Hansson GK. Oligoclonal T cell expansions in atherosclerotic lesions of apolipoprotein E-deficient mice. Arterioscler Thromb Vasc Biol 2000;20(01):10-17

40 Lin Z, Qian S, Gong Y, et al. Deep sequencing of the T cell receptor $\beta$ repertoire reveals signature patterns and clonal drift in atherosclerotic plaques and patients. Oncotarget 2017;8(59): 99312-99322

41 Fredrikson GN, Hedblad B, Berglund G, et al. Identification of immune responses against aldehyde-modified peptide sequences in ApoB associated with cardiovascular disease. Arterioscler Thromb Vasc Biol 2003;23(05):872-878

42 Tsiantoulas D, Diehl CJ, Witztum JL, Binder CJ. B cells and humoral immunity in atherosclerosis. Circ Res 2014;114(11): 1743-1756

43 Sage AP, Tsiantoulas D, Binder CJ, Mallat Z. The role of B cells in atherosclerosis. Nat Rev Cardiol 2019;16(03):180-196

44 Song L, Leung C, Schindler C. Lymphocytes are important in early atherosclerosis. J Clin Invest 2001;108(02):251-259

45 Dansky HM, Charlton SA, Harper MM, Smith JDT. T and B lymphocytes play a minor role in atherosclerotic plaque formation in the apolipoprotein E-deficient mouse. Proc Natl Acad Sci U S A 1997;94(09):4642-4646

46 Zhou X, Robertson AK, Hjerpe C, Hansson GK. Adoptive transfer of CD4+ T cells reactive to modified low-density lipoprotein aggravates atherosclerosis. Arterioscler Thromb Vasc Biol 2006; 26(04):864-870

47 Wigren M, Rattik S, Yao Mattisson I, et al. Lack of ability to present antigens on major histocompatibility complex class II molecules aggravates atherosclerosis in $\mathrm{ApoE}^{-1-}$ mice. Circulation 2019;139(22):2554-2566

48 Ley K. 2015 Russell Ross Memorial Lecture in vascular biology: protective autoimmunity in atherosclerosis. Arterioscler Thromb Vasc Biol 2016;36(03):429-438

49 Winkels H, Ehinger E, Ghosheh Y, Wolf D, Ley K. Atherosclerosis in the single-cell era. Curr Opin Lipidol 2018;29(05):389-396

50 Nettersheim FS, De Vore L, Winkels H. Vaccination in atherosclerosis. Cells 2020;9(12):E2560

51 Wolf D, Gerhardt T, Ley K. Vaccination to prevent cardiovascular disease. In: Cardiac and Vascular Biology. Springer International Publishing; 2017:29-52

52 Wick G, Jakic B, Buszko M, Wick MC, Grundtman C. The role of heat shock proteins in atherosclerosis. Nat Rev Cardiol 2014;11 (09):516-529

53 Zhu J, Quyyumi AA, Rott D, et al. Antibodies to human heatshock protein 60 are associated with the presence and severity of coronary artery disease: evidence for an autoimmune component of atherogenesis. Circulation 2001;103(08): 1071-1075

54 Wick C. Tolerization against atherosclerosis using heat shock protein 60. Cell Stress Chaperones 2016;21(02):201-211

55 Perschinka H, Mayr M, Millonig G, et al. Cross-reactive B-cell epitopes of microbial and human heat shock protein 60/65 in atherosclerosis. Arterioscler Thromb Vasc Biol 2003;23(06): 1060-1065

56 Binder CJ, Hörkkö S, Dewan A, et al. Pneumococcal vaccination decreases atherosclerotic lesion formation: molecular mimicry between Streptococcus pneumoniae and oxidized LDL. Nat Med 2003;9(06):736-743

57 Tsutsumi A, Matsuura E, Ichikawa K, et al. Antibodies to beta 2glycoprotein I and clinical manifestations in patients with systemic lupus erythematosus. Arthritis Rheum 1996;39(09): 1466-1474

58 Kandiah DA, Krilis SA. Beta 2-glycoprotein I. Lupus 1994;3(04): 207-212

59 George J, Harats D, Gilburd B, et al. Immunolocalization of beta2glycoprotein I (apolipoprotein $\mathrm{H}$ ) to human atherosclerotic plaques: potential implications for lesion progression. Circulation 1999;99(17):2227-2230

60 De Haro J, Esparza L, Bleda S, Varela C, Sanchez C, Acin F. Attenuation of early atherosclerotic lesions by immunotolerance with $\beta 2$ glycoprotein I and the immunomodulatory effectors interleukin 2 and 10 in a murine model. J Vasc Surg 2015;62(06): $1625-1631$

61 McDonnell T, Wincup C, Buchholz I, et al. The role of beta-2glycoprotein I in health and disease associating structure with function: more than just APS. Blood Rev 2020;39:100610

62 Shah PK. Inflammation, infection and atherosclerosis. Trends Cardiovasc Med 2019;29(08):468-472

63 Udell JA, Zawi R, Bhatt DL, et al. Association between influenza vaccination and cardiovascular outcomes in high-risk patients: a meta-analysis. JAMA 2013;310(16):1711-1720

64 Macintyre CR, Heywood AE, Kovoor P, et al. Ischaemic heart disease, influenza and influenza vaccination: a prospective case control study. Heart 2013;99(24):1843-1848

65 Rosenfeld ME, Campbell LA. Pathogens and atherosclerosis: update on the potential contribution of multiple infectious organisms to the pathogenesis of atherosclerosis. Thromb Haemost 2011;106(05):858-867

66 Naghavi M, Wyde P, Litovsky S, et al. Influenza infection exerts prominent inflammatory and thrombotic effects on the atherosclerotic plaques of apolipoprotein E-deficient mice. Circulation 2003;107(05):762-768 
67 Hendren NS, Drazner MH, Bozkurt B, Cooper LT Jr. Description and proposed management of the acute COVID-19 cardiovascular syndrome. Circulation 2020;141(23):1903-1914

68 Libby P. The heart in COVID-19: primary target or secondary bystander? JACC Basic Transl Sci 2020;5(05):537-542

69 Varga Z, Flammer AJ, Steiger P, et al. Endothelial cell infection and endotheliitis in COVID-19. Lancet 2020;395(10234):1417-1418

70 Lindner D, Fitzek A, Bräuninger $\mathrm{H}$, et al. Association of cardiac infection with SARS-CoV-2 in confirmed COVID-19 autopsy cases. JAMA Cardiol 2020;5(11):1281-1285

71 Gero S, Gergely J, Jakab L, et al. Inhibition of cholesterol atherosclerosis by immunisation with beta-lipoprotein. Lancet 1959;2 (7088):6-7

72 Freigang S, Hörkkö S, Miller E, Witztum JL, Palinski W. Immunization of LDL receptor-deficient mice with homologous malondialdehyde-modified and native LDL reduces progression of atherosclerosis by mechanisms other than induction of high titers of antibodies to oxidative neoepitopes. Arterioscler Thromb Vasc Biol 1998;18(12):1972-1982

73 Palinski W, Miller E, Witztum JL. Immunization of low density lipoprotein (LDL) receptor-deficient rabbits with homologous malondialdehyde-modified LDL reduces atherogenesis. Proc Natl Acad Sci U S A 1995;92(03):821-825

74 Ameli S, Hultgårdh-Nilsson A, Regnström J, et al. Effect of immunization with homologous LDL and oxidized LDL on early atherosclerosis in hypercholesterolemic rabbits. Arterioscler Thromb Vasc Biol 1996;16(08):1074-1079

75 George J, Afek A, Gilburd B, et al. Hyperimmunization of apo-Edeficient mice with homologous malondialdehyde low-density lipoprotein suppresses early atherogenesis. Atherosclerosis 1998;138(01):147-152

76 Zhou X, Caligiuri G, Hamsten A, Lefvert AK, Hansson GK. LDL immunization induces T-cell-dependent antibody formation and protection against atherosclerosis. Arterioscler Thromb Vasc Biol 2001;21(01):108-114

77 Chyu KY, Reyes OS, Zhao X, et al. Timing affects the efficacy of LDL immunization on atherosclerotic lesions in apo $\mathrm{E}(-/-)$ mice. Atherosclerosis 2004;176(01):27-35

78 Zhou X, Robertson AK, Rudling M, Parini P, Hansson GK. Lesion development and response to immunization reveal a complex role for CD4 in atherosclerosis. Circ Res 2005;96(04): 427-434

79 Zhong Y, Wang X, Ji Q et al. CD4+LAP + and CD4 +CD25 + Foxp3 + regulatory $\mathrm{T}$ cells induced by nasal oxidized low-density lipoprotein suppress effector $\mathrm{T}$ cells response and attenuate atherosclerosis in ApoE-/- mice. J Clin Immunol 2012;32(05): 1104-1117

80 Kobiyama K, Saigusa R, Ley K. Vaccination against atherosclerosis. Curr Opin Immunol 2019;59:15-24

81 Tse K, Gonen A, Sidney J, et al. Atheroprotective vaccination with MHC-II restricted peptides from ApoB-100. Front Immunol 2013;4:493

82 Kimura T, Tse K, McArdle S, et al. Atheroprotective vaccination with MHC-II-restricted ApoB peptides induces peritoneal IL-10producing CD4 T cells. Am J Physiol Heart Circ Physiol 2017;312 (04):H781-H790

83 Klingenberg R, Lebens M, Hermansson A, et al. Intranasal immunization with an apolipoprotein B-100 fusion protein induces antigen-specific regulatory $T$ cells and reduces atherosclerosis. Arterioscler Thromb Vasc Biol 2010;30(05):946-952

84 Gisterå A, Hermansson A, Strodthoff D, et al. Vaccination against T-cell epitopes of native ApoB100 reduces vascular inflammation and disease in a humanized mouse model of atherosclerosis. J Intern Med 2017;281(04):383-397

85 Hermansson A, Johansson DK, Ketelhuth DF, Andersson J, Zhou X, Hansson GK. Immunotherapy with tolerogenic apolipoprotein B-100-loaded dendritic cells attenuates atherosclerosis in hypercholesterolemic mice. Circulation 2011;123(10):1083-1091
86 Kobiyama K, Vassallo M, Mitzi J, et al. A clinically applicable adjuvant for an atherosclerosis vaccine in mice. Eur $\mathrm{J}$ Immunol 2018;48(09):1580-1587

87 Wigren M, Bengtsson D, Dunér P, et al. Atheroprotective effects of Alum are associated with capture of oxidized LDL antigens and activation of regulatory T cells. Circ Res 2009;104(12):e62-e70

88 Herbin O, Ait-Oufella $\mathrm{H}$, Yu W, et al. Regulatory T-cell response to apolipoprotein B100-derived peptides reduces the development and progression of atherosclerosis in mice. Arterioscler Thromb Vasc Biol 2012;32(03):605-612

89 Marchini T, Mitre LS, Wolf D. Inflammatory cell recruitment in cardiovascular disease. Front Cell Dev Biol 2021;9:635527

90 Shaw MK, Tse KY, Zhao X, et al. T-cells specific for a self-peptide of ApoB-100 exacerbate aortic atheroma in murine atherosclerosis. Front Immunol 2017;8:95

91 Schulien I, Kemming J, Oberhardt V, et al. Characterization of pre-existing and induced SARS-CoV-2-specific $\mathrm{CD}^{+} \mathrm{T}$ cells. Nat Med 2021;27(01):78-85

92 Lorenzo C, Delgado P, Busse CE, et al. ALDH4A1 is an atherosclerosis auto-antigen targeted by protective antibodies. Nature 2021;589(7841):287-292

93 Davenport P, Tipping PG. The role of interleukin-4 and interleukin-12 in the progression of atherosclerosis in apolipoprotein E-deficient mice. Am J Pathol 2003;163(03):1117-1125

94 Hauer AD, Uyttenhove C, de Vos P, et al. Blockade of interleukin12 function by protein vaccination attenuates atherosclerosis. Circulation 2005;112(07):1054-1062

95 Mach F, Baigent C, Catapano AL, et al; ESC Scientific Document Group. 2019 ESC/EAS guidelines for the management of dyslipidaemias: lipid modification to reduce cardiovascular risk. Eur Heart J 2020;41(01):111-188

96 McPherson R, Tybjaerg-Hansen A. Genetics of coronary artery disease. Circ Res 2016;118(04):564-578

97 Crossey E, Amar MJA, Sampson M, et al. A cholesterol-lowering VLP vaccine that targets PCSK9. Vaccine 2015;33(43): 5747-5755

98 Gaofu Q Jun L, Xin Y, et al. Vaccinating rabbits with a cholesteryl ester transfer protein (CETP) B-Cell epitope carried by heat shock protein-65 (HSP65) for inducing anti-CETP antibodies and reducing aortic lesions in vivo. J Cardiovasc Pharmacol 2005;45 (06):591-598

99 Rittershaus CW, Miller DP, Thomas LJ, et al. Vaccine-induced antibodies inhibit CETP activity in vivo and reduce aortic lesions in a rabbit model of atherosclerosis. Arterioscler Thromb Vasc Biol 2000;20(09):2106-2112

100 Pulendran B, Davis MM. The science and medicine of human immunology. Science 2020;369(6511):eaay4014

101 Greenwood B. The contribution of vaccination to global health: past, present and future. Philos Trans R Soc Lond B Biol Sci 2014; 369(1645):20130433

102 Moorman CD, Sohn SJ, Phee H. Emerging therapeutics for immune tolerance: tolerogenic vaccines, $t$ cell therapy, and IL-2 therapy. Front Immunol 2021;12:657768

103 Han A, Glanville J, Hansmann L, Davis MM. Linking T-cell receptor sequence to functional phenotype at the single-cell level. Nat Biotechnol 2014;32(07):684-692

104 Reed SG, Orr MT, Fox CB. Key roles of adjuvants in modern vaccines. Nat Med 2013;19(12):1597-1608

105 Guimarães LE, Baker B, Perricone C, Shoenfeld Y. Vaccines, adjuvants and autoimmunity. Pharmacol Res 2015;100:190-209

106 Kimura T, Tse K, Sette A, Ley K. Vaccination to modulate atherosclerosis. Autoimmunity 2015;48(03):152-160

107 Tse K, Gonen A, Sidney J, et al. Atheroprotective Vaccination with MHC-II Restricted Peptides from ApoB-100. Front Immunol 2013;4:493

108 Brunner R, Jensen-Jarolim E, Pali-Schöll I. The ABC of clinical and experimental adjuvants-a brief overview. Immunol Lett 2010; 128(01):29-35 
109 Khallou-Laschet J, Tupin E, Caligiuri G, et al. Atheroprotective effect of adjuvants in apolipoprotein $\mathrm{E}$ knockout mice. Atherosclerosis 2006;184(02):330-341

110 Engman C, Wen Y, Meng WS, Bottino R, Trucco M, Giannoukakis $\mathrm{N}$. Generation of antigen-specific Foxp3+ regulatory T-cells in vivo following administration of diabetes-reversing tolerogenic microspheres does not require provision of antigen in the formulation. Clin Immunol 2015;160(01):103-123

111 Long J, Lin J, Yang X, et al. Nasal immunization with different forms of heat shock protein-65 reduced high-cholesterol-dietdriven rabbit atherosclerosis. Int Immunopharmacol 2012;13 (01):82-87

112 van Puijvelde GH, van Es T, van Wanrooij EJ, et al. Induction of oral tolerance to HSP60 or an HSP60-peptide activates T cell regulation and reduces atherosclerosis. Arterioscler Thromb Vasc Biol 2007;27(12):2677-2683

$113 \mathrm{Xu}$ Q Dietrich H, Steiner HJ, et al. Induction of arteriosclerosis in normocholesterolemic rabbits by immunization with heat shock protein 65. Arterioscler Thromb 1992;12(07):789-799

114 George J, Shoenfeld Y, Afek A, et al. Enhanced fatty streak formation in C57BL/6J mice by immunization with heat shock protein-65. Arterioscler Thromb Vasc Biol 1999;19(03):505-510

115 Peikert A, Kaier K, Merz J, et al. Residual inflammatory risk in coronary heart disease: incidence of elevated high-sensitive CRP in a real-world cohort. Clin Res Cardiol 2020;109(03):315-323

116 Walczak A, Szymanska B, Selmaj K. Differential prevention of experimental autoimmune encephalomyelitis with antigen-specific DNA vaccination. Clin Neurol Neurosurg 2004;106(03):241-245

117 Kutzler MA, Weiner DB. DNA vaccines: ready for prime time? Nat Rev Genet 2008;9(10):776-788

118 Shen Y, Chen J, Zhang X, Wu X, Xu Q. Human TNF-alpha gene vaccination prevents collagen-induced arthritis in mice. Int Immunopharmacol 2007;7(09):1140-1149

119 Hauer AD, van Puijvelde GH, Peterse N, et al. Vaccination against VEGFR2 attenuates initiation and progression of atherosclerosis. Arterioscler Thromb Vasc Biol 2007;27(09):2050-2057

120 Pardi N, Hogan MJ, Porter FW, Weissman D. mRNA vaccines - a new era in vaccinology. Nat Rev Drug Discov 2018;17(04):261-279

121 Krienke C, Kolb L, Diken E, et al. A noninflammatory mRNA vaccine for treatment of experimental autoimmune encephalomyelitis. Science 2021;371(6525):145-153
122 Kimura T, Tse K, McArdle S, et al. Atheroprotective vaccination with MHC-II-restricted ApoB peptides induces peritoneal IL-10producing CD4 T cells. Am J Physiol Heart Circ Physiol 2017;312 (04):H781-H790

123 Gistera A, Klement ML, Polyzos KA, et al. LDL-reactive T cells regulate plasma cholesterol levels and development of atherosclerosis in humanized hypercholesterolemic mice. Circulation 2018;138(22):2513-2526

124 Tay C, Liu YH, Kanellakis P, et al. Follicular B cells promote atherosclerosis via $\mathrm{T}$ cell-mediated differentiation into plasma cells and secreting pathogenic immunoglobulin G. Arterioscler Thromb Vasc Biol 2018;38(05):e71-e84

125 Schiopu A, Bengtsson J, Söderberg I, et al. Recombinant human antibodies against aldehyde-modified apolipoprotein B-100 peptide sequences inhibit atherosclerosis. Circulation 2004; 110(14):2047-2052

126 Schiopu A, Frendéus B, Jansson B, et al. Recombinant antibodies to an oxidized low-density lipoprotein epitope induce rapid regression of atherosclerosis in Apobec-1(-/-)/low-density lipoprotein receptor(-/-) mice. J Am Coll Cardiol 2007;50(24): 2313-2318

127 Li S, Kievit P, Robertson AK, et al. Targeting oxidized LDL improves insulin sensitivity and immune cell function in obese Rhesus macaques. Mol Metab 2013;2(03):256-269

128 Lehrer-Graiwer J, Singh P, Abdelbaky A, et al. FDG-PET imaging for oxidized LDL in stable atherosclerotic disease: a phase II study of safety, tolerability, and anti-inflammatory activity. JACC Cardiovasc Imaging 2015;8(04):493-494

129 June CH, O'Connor RS, Kawalekar OU, Ghassemi S, Milone MC. CAR T cell immunotherapy for human cancer. Science 2018;359 (6382):1361-1365

130 Mullard A. FDA approves first CAR T therapy. Nat Rev Drug Discov 2017;16(10):669

131 Aghajanian H, Kimura T, Rurik JG, et al. Targeting cardiac fibrosis with engineered T cells. Nature 2019;573(7774):430-433

132 Zhao TX, Kostapanos M, Griffiths C, et al. Low-dose interleukin-2 in patients with stable ischaemic heart disease and acute coronary syndromes (LILACS): protocol and study rationale for a randomised, double-blind, placebo-controlled, phase I/II clinical trial. BMJ Open 2018;8(09):e022452 